China Perspectives

2011/3 | 2011

Chinese Medicine: The Global Influence of an Evolving Heritage

\title{
The Characteristics of Korean Medicine Based on
} Time Classification

\section{Kang Yeonseok}

\section{(2) OpenEdition}

\section{Journals}

Electronic version

URL: http://journals.openedition.org/chinaperspectives/5630

DOI: 10.4000/chinaperspectives.5630

ISSN: 1996-4617

\section{Publisher}

Centre d'étude français sur la Chine contemporaine

Printed version

Date of publication: 1 October 2011

Number of pages: 33-41

ISSN: 2070-3449

\section{Electronic reference}

Kang Yeonseok, "The Characteristics of Korean Medicine Based on Time Classification », China Perspectives [Online], 2011/3 | 2011, Online since 30 September 2014, connection on 28 October 2019. URL : http://journals.openedition.org/chinaperspectives/5630; DOI : 10.4000/chinaperspectives.5630 


\title{
The Characteristics of Korean
}

\section{Medicine Based on Time}

\section{Classification}

\author{
KANG YEONSEOK*
}

\begin{abstract}
Korea's exchanges with the West only effectively began after World War II. This makes the situation in Korea very different from that of China or Japan, where various exchanges with Western countries were already being carried out in the sixteenth century. The introduction of modernised research methods was also delayed. Nevertheless, Korean medicine (KM) has been well modernised, while at the same time traditional medicine, less tainted by the wave of modernisation, has been preserved. Moreover, KM is now attracting young and capable talent of a kind never before seen in this field. Often reduced in Chinese official discourse to a mere variant of Traditional Chinese Medicine (TCM), KM in fact constitutes a tradition of its own. This paper tracks the history of KM using time classification in order to better inform Western society regarding KM.
\end{abstract}

The history of KM can be divided into the following five time periods: 1) The time of local medicine (for which all medical records have been lost); 2) the time of Hyangyak medicine (i.e., medicine made solely from medicinal herbs grown in Korea); 3) the time of compilation of East Asian Medicines; 4 ) the time of independent formation of KM; and 5) the time of exchange with modern medicine.**

KEYWORDS: Korean Medicine (KM), Oriental Medicine, Hyangyak medicine (local drugs medicine), history of KM, time classification, TCM.

T his paper has been written to inform Western scholars of the differences between Korean Medicine (KM) and Chinese Medicine. Since $\mathrm{KM}$ and Chinese Medicine are the products of processes as long as the histories of both countries, while influencing each other throughout, understanding the history of KM should provide a shortcut to understanding the differences between these two medicines.

The two most important texts in the history of KM are History of Korean Medicine and of Diseases in Korea (朝鮮醫學史及疾病史 $)^{(1)}$ and The History of Korean Medicine (韓國醫學史). (2)

The former was written by Sakae Miki (三木榮 1903-1992), the first researcher to study the history of KM. He wrote his book from a positivist's point of view, referring directly to numerous Korean medical texts. His description of KM is so comprehensive that it forms the basis for all subsequent research on the history of KM. However, the time he was active as a historian was when a imperialistic historical view prevailed as a means to justify Japan's colonisation of Korea. Ultimately, Miki's description imposed this erroneous perspective on KM history.

The latter text is by Doojong Kim (1896-1988), who also compiled numerous primary historical records. Although he attempted to overcome Miki's viewpoint, he had similar limitations. Moreover, both were doctors of Western medicine educated in Japan before they studied history. Because they tended to interpret KM from a Western medical perspective, they sometimes emphasised the unreasonable rather than the positive aspects of $\mathrm{KM}^{(3)}$ a tendency more apparent in Kim than in Miki. ${ }^{(4)}$

The two books mentioned above describe Korean medical history using a time classification based on the names of Korean dynasties. While this is helpful in grasping the medical concepts, organisation, and economical systems of each dynasty, it may not be suitable for understanding the medicine itself and its process of development. ${ }^{(5)}$

The present paper will adopt a time classification that treats major medical texts as turning points, for three reasons: First, the most important content can be introduced through representative texts; second, it is a good way to clarify the differences between KM and TCM; third, it also ad-

Kang Yeonseok is Korean Medical Doctor (KMD), assistant Professor, Department of Medical History, College of Korean Medicine, Wonkwang University, Iksan City, Jeonrabuk-do, Korea, 570-749 (yeonkang@wku.ac.kr).

** This work has been supported by the National Research Foundation of Korea (NRF) and a grant funded by the Korean Covernment (MEST) (NRF-2010-361-A00008). The author also thanks Moon Wonkyung of Kyunghee University, College of Korean Medicine, for assistance with the English translation of this paper.

1. In the present paper, the pinyin pronunciation of bibliographic references and terms in Chinese characters will be indicated only when they refer to Chinese readings. When referring mainly to Korean or Japanese readings, no phonetic transcription will be given. Transcriptions of Korean terms are followed by "kor. trans." for "Korean transcription" when they appear for the first time.

2. Shin Dongwon, "Trends in Research on the History of Medicine in Korea before the Modern Era," Korean Journal of Medical History, vol. 19, 2010.

3. Kim Namll, "History of Korean Medicine seen from Donguibogam 1-54," homepage of the Organization for the Commemoration of 400th Year Since the Publication of Donguibogam (www.dongui400.or.kr/community), 2009-2011; Shin Dongwon, "Miki Sakae's Study on History of Korean Medicine: Accomplishment and limitations," Research of History and Culture, special edition, 2005; Yeo In-sok, "Kim Doo-jong: A Life for the History of Korean Medicine," Korean Journal of Medical History, vol. 7, 1998, pp. 1-11; Kim Hongkyoon, "Berating on the Historical view in Korea dynasty's Medicine (1)," Korean Journal of Oriental Medicine, vol. 9, no. 1, 2003, pp. 1-33.

4. Kang Yeonseok, "Rewriting the History of Korean Medicine: Assessments of Donguibogam and Two Perspectives of Looking at Korean Medicine," Ohmynews, vol. 9, 2009; Kim JaeHyo et al., "The Existence and Role of ji-chong for Medical Exchange in Ancient Korea," The Journal of Korean Oriental Medicine, vol. 28, no. 3, 2007, pp. 70-85.

5. Shin Dongwon, op. cit. 
dresses problems of historical perspective in KM history. The five periods will be presented in chronological order.

\section{Period of loss of medical texts ( twelfth century)}

This period was a time of exchanges between local medicine and various medicines from overseas. In terms of Korean history, it includes the states of Chosun (kor. trans. of 朝鮮, 2333 - 108 B.C.), as well as Buyeo (kor. trans. of 扶餘, 200 B.C. - 494 A.D.), Go(gu)ryeo (kor. trans. of 高(句)麗, 200 B.C. 668 A.D.), Baekje (kor. trans. of 百濟, 100 B.C. - 660 A.D.), Shilla (kor. trans. of 新羅, first century B.C. - 935 A.D. ), Balhae (kor. trans. of 渤海, 698 926), and Goryeo (kor. trans. of 高麗, 918-1392). These countries were located in the Korean peninsula as well as what now constitutes the Chinese provinces of Liaoning, Jilin, and Heilongjiang.

As no primary medical records of this time up to the twelfth century have survived, medical activity can only be inferred from general historical documents of Korea, China, and Japan. The fact that there are many records of $\mathrm{KM}$ in other countries indicates the extent of medical exchanges at that time.

The history of KM begins with the founding of the nation. According to a story in the late thirteenth-century work Handed-down Stories of Three Countries (三國遺事), a bear and a tiger made a wish to God, who especially loved the human world, and said that they would like to become humans. God told them to eat only mugwort and wild rocambole (or garlic) and to live in a cave for a hundred days. The tiger failed, but the bear succeeded and turned into a woman. The woman married Cod and gave birth to a son who later founded Chosun.

This short story includes various medical themes such as: 1) "efficiency of Materia Medica" (although exaggerated), depicted in the affect of medicinal herbs such as mugwort and wild rocambole (or garlic) on living beings; 2) "medical taboos" such as avoiding sunlight and living in a cave for 100 days for the anticipated efficacy; 3 ) "living environment," such as the cave; 4) "the concept of yin and yang" as depicted by God and human, man and woman, and sunny spots and shady spots; 5) "knowledge of Materia Medica" as inferred by the use of "warm drugs" (6) (mugwort, wild rocambole, or garlic) that would have been appropriate for living in a dark and damp cave; 6 ) and finally "the role of doctor and patient" as embodied by one who heals and prescribes and others who are healed and obtain prescribed drugs. ${ }^{(7)}$

The reason these medical themes are included in the story of the foundation of Korea is probably due to the longstanding practice of Korean doctors using local herbs to cure their patients.

The major classic of TCM, the Internal Classic of the Yellow Emperor (黃帝 內經), says that a stone needle came from the east. This record, which conveys the idea that the ethnic group that lived on the eastern side of China first developed stone needles suited to their climate, food, and illnesses, can be regarded as a possible allusion to the origins of Korean medicine. ${ }^{(8)}$

Historical books such as the Historical Records of Three Countries (三國 史記 ), written in 1145, or the Handed-down Stories of Three Countries, provide valuable information on the influx of medicinal herbs from Persia, India, and Southeast Asia between the fifth and tenth centuries, as well as the treatment of Chinese and Japanese patients by Korean doctors, various names of diseases, some names of medical official posts, medical aid for the poor, and measures against communicable diseases.
The History of Goryeo (高麗史), written in the fifteenth century, includes more detailed records from the tenth to the fourteenth centuries than earlier works. It speaks of medical education and the enforcement of state examinations in eleventh-century Goryeo, gives detailed names of official posts, and describes measures against communicable diseases. Doctors were dispatched to battlefields, soldiers were treated by medical officials when they became ill, corpses were handed over to family members with their belongings, funerals were conducted at state expense, and veterinarians were recruited to serve as government officials. ${ }^{(9)}$

Miki described the KM of this period as a process of importing Chinese medicine. Kim said that even though most medical knowledge was imported from China, some herbs were exported to China. However, many scholars have recently shed light on the medical history of East Asia, with a focus on the exchange of medical knowledge. ${ }^{(10)}$

Prescriptions from an Elderly Saint of Goryeo (高麗老師方), the New Collection of Prescriptions from Baekjae (白濟新集方), Prescriptions by a Priest from Shilla (新羅法師方), Secret and Magical Prescriptions by a Priest from Shilla (新羅法師流觀秘密要術方), and Secret Prescriptions by a Priest from Shilla (新羅法師秘密方) are all well-known texts written during this period, and some prescriptions found in these texts appear in classical texts of TCM such as Essential Prescriptions Worth a Thousand Pieces of Gold (千金方) and Medical Secrets of an Official (外臺密要), and in Japan's Formulary from the Heart of Medicine (醫心方), which allows some inference of the content of the aforementioned texts. For example, the Formulary from the Heart of Medicine mentions the prescription of wasp nest (露蜂房 - Lufeng fang) (11) in Secret Prescriptions by a Priest from Shilla, and this is known to be a unique prescription not found in Chinese or Japanese practice. ${ }^{(12)}$

Much of the medical content of that era can be found in the Re-edited Classified Materia Medica (重修政和經史證類備用本草), compiled by Zhang Cunhui (張存慧) in 1189. This book is considered a more important reference for studying Korean medical history than the chinese Compendium of Materia Medica (本草綱目) because it affected Korean Medicine tremendously and has more records of KM. ${ }^{(13)}$

More than 40 kinds of herbal medicine recorded in this book are associated with Korea in terms of the names of countries and of regions such as Dongin ( kor. trans. of 東人) and Donghae (kor. trans. of 東海). The Chinese regarded these Korean herbs as superior at that time; it can be said that Korean doctors had a greater wealth of knowledge regarding clinical practice than their Chinese counterparts, at least in terms of these herbs. This

6. In Korean Medicine, drugs are classified into "warm drugs" and "cold drugs" according to whether they make a patient feel warm or cold.

7. Maeng Woongjae et al., General History of Korean Medicine, Daesung publish company, Seoul, 2006.

8. Kim Jaehyo et al, "Archeological Quest on the Origin and Formation of the Stone Needle in the Korean Peninsula," Korean Journal of Oriental Medicine, vol. 15, no. 2, 2009, pp. 51-62; cf." Yifa fangyi lunpian," ch. 12, Huangdi neijing (Suwen).

9. Kim Doo-Jong, The History of Korean Medicine, pp. 115-116, 135-136, 149-151, op. cit; Maeng Woongjae et al., pp. 118-130, op. cit., pp. 118-130.

10. Liu Chang-Hua, "The birthplace of Chinese medicine and the process of fusion," Journal of Korean Medical History, vol. 22, no. 2, 2009; Zheng Jinsheng, "Facilitating exchanges among traditional medicine of China, Japan, Korea, and Vietnam," in Sourcebook of the 2nd Combined Symposium of Societies of Traditional Medicine in Japan, China, and Korea, 2010.

11. Editor's note: This refers to the nest of Polistes mandarinus Saussure (a wasp belonging to the Vespidae family). The nest is dried before using (without the insect).

12. Kim Doo-Jong, op. cit.

13. Kang YeonSeok, "An examination of the indigenous medicinal herbs that appear in Zhongxiuzheng huo jingshi zhenglei beiyong bencao ( 重修政和經史證類備用本草)," Journal of Korean Medical History, vol. 17, no. 2, 2004, pp. 63-72. 
leads to the inference that Traditional Korean Medicine started out from the practice of curing the illnesses of Korean people, using herbs native to Korea, and that in the process, some prominent cases were recorded in the medical texts of China and Japan.

This book includes an example of transfer of medical knowledge and clinical experience from the state of Shilla to the Tang Empire. A patient in Shangzhou of Tang could not walk due to serious illness. Cure had eluded him for decades, although he had sought out the best doctors throughout China. One day, he chanced upon a monk from Shilla. The monk said, "There is an herb that can cure your illness, but I am not sure if it can be found here." He then climbed a mountain and found the herb, called Clematidis Radix (藏靈仙 - weilingxian). After taking it for several days, the patient was able to walk again. ${ }^{(14)}$

\section{Period of "Hyangyak Medicine" (thirteenth to fifteenth centuries)}

"Hyangyak" ( kor. trans. of 鄉藥 - local drugs) means medicinal material grown naturally and cultivated in Korea. "Hyangyak medicine" is a type of KM that prescribes only Hyangyak. The period during which this medical tradition was mainly used (thirteenth to fifteenth centuries) was a time of active fusion of local medicine using domestic herbs with medical knowledge from overseas.

This period covers late Goryeo (thirteenth to fifteenth centuries) and early Chosun (fifteenth century) history. Goryeo (918-1392) was a Buddhist country in an antagonistic relationship with northern nations such as Liao, Jin, and Yuan, while on friendly terms with Song. Its territory was that of the current North and South Korea combined. Chosun (1392-1910), a country based on Neo-Confucianism and closely allied with Ming, was located in the current North and South Korean territory along with some parts of China's present jilin region.

The earliest extant record of KM is Emergency Prescriptions from the Countryside (鄉藥救急方), which is known to have been written in the early thirteenth century. ${ }^{(15)}$ It is assumed that other medical texts such as Effective Prescriptions for Universal Relief (濟衆立效方), A Hundred Essential Prescriptions for Prevention (備預百要方), Experiential Prescriptions of a Man from the East (東人經驗方), as well as Old Prescriptions of Countryside Medicine (鄉藥古方), Experiential Prescriptions of Countryside Medicine (鄉藥慧民經驗方), Prescriptions of Countryside Medicine by Samhwaja (三和子鄉藥慧方), Simple Prescriptions of Countryside Medicine (鄉藥易簡 方 or 鄉藥簡易方), Compendium of Prescriptions from the Countryside for Universal Relief (鄉藥濟生集成方 1399), and Compendium of Prescriptions from the Countryside (鄉藥集成方 1433), were also published during this period. As can be inferred from the names of the books, "Hyangyak (鄉藥)" was an important task for medical society at that time.

Hyangyak Medicine has several characteristics: ${ }^{(16)}$ First, it mainly uses prescriptions utilising herbs native to or cultivated in Korea. Second, only one or two drugs are used. Third, raw and fresh materials are often used. Fourth, its focus is on medical treatments and herbs that are quickly applied, inexpensive, and easily acquired. Fifth, it aims for a high utilisation rate in medically underserved areas. Sixth, it applies the method of food therapy.

Miki and Kim gave high appraisals to Hyangyak medicine, saying that it originated in Korea, which means that "Hyangyak medicine" is a medicine autogenous to Korea. They commented in particular on the Compendium of Prescriptions from the Countryside, saying that it was a compilation of unique medicine ${ }^{(17)}$ and that it created independence from medicinal herbs from China. ${ }^{(18)}$ However, this was a conclusion drawn from four completely incorrect premises that: 1) all KM was introduced from China; 2) unique KM first appeared in the form of Hyangyak in the Goryeo period; 3) KM became independent of Chinese medicine only after the early Chosun period; and 4) all Hyangyak medicine has the same characteristics. It is meaningless to ask what is unique to or originated in Korea, because Chinese medicine absorbed the medical knowledge of adjoining countries, including Korea, as it developed over time, and hundreds of years passed before Chinese medicine was re-absorbed into Korean medicine. Also, referring to unique medicine at this time is meaningless, because the Shilla and Tang states, as well as the countries of Goryeo and Song, were politically, economically, and culturally closer to each other than to any other countries. Medical texts on Hyangyak medicine include medicine from Shilla that dates back to at least the eighth to ninth centuries, and some of them were even republished in mid-seventeenth-century Chosun. Different social and cultural factors explain the publication of these texts, as a result of which they cannot be reduced to a single characteristic. Following its creation in Korea, Hyangyak medicine actively absorbed local medical traditions during the fourteenth and fifteenth centuries. Since Hyangyak medicine has been under the influence of several foreign medical traditions during its development, it is inaccurate to consider it a uniquely Korean medicine. (19) Presumably this misunderstanding came about because there are no extant texts older than those about Hyangyak, and because of the misconceptions of Miki and Kim, who regarded preHyangyak KM as primitive.

In the thirteenth century, from 1231 to 1270 , there was war between Goryeo and Yuan. Emergency Prescriptions from the Countryside was published by a government body called the Daejangdogam (kor. trans. of 大藏 都監), which was established in 1236 during this time of war. It was a government office devoted to defeating Mongolia with the help of Buddha by publishing A collection of all the sacred writings of Buddhism (大藏經). Practicing medicine with medicinal herbs imported from the country with which Goryeo was at war was no easy task. Thus, a medical text was published in hopes of overcoming this problem with the herbal resources available to Korean people at that time. It was inevitable, therefore, that medicine regressed to the time of local medicine using herbs that could easily be found within Korea.

With the arrival of the fourteenth century, circumstances changed: rather than making war with the Chinese Yuan empire, Goryeo began to adapt to a new world order with Yuan at the centre. This trend arrested the development of Hyangyak medicine. However a man called Saryang Bang became deeply involved in the medical policies of Goryeo and Chosun, and insisted on strengthening sovereign power by stabilising dynastic finances, urging people to live frugally, and in particular banning costly goods im-

14. Maeng Woongjae et al., op. cit., pp. 194-198.

15. Shin Youngll, Research on Compendium of Prescriptions from the Countryside, Kyunghee University, PhD dissertation, 1995.

16. Kang YeonSeok, The Study of HyangYak Medicine through HyangYakJipSeongBang, Kyunghee University, PhD dissertation, 2006.

17. Miki Sakae, History of Korean medicine and of diseases in Korea, 1955.

18. Kim Doo-Jong, op. cit.

19. Kang YeonSeok, "The Writings of HyangYaklipSungBang (鄉藥集成方) and Medical Exchanges between Korea and China during the 15th Century," Journal of Korean Oriental Medicine, vol. 29, no. 4, 2008, pp. 213-217. 
ported from China. Accordingly, Bang, a medical official, emphasised Hyangyak and helped compile the Compendium of Prescriptions from the Countryside for Universal Relief in 1399 in order to stabilise the national medical system as well as the medical finances at the foundation of the Chosun dynasty in 1392. (20)

The stabilisation of the Chosun dynasty in the fifteenth century brought another change of circumstances. King Sejong (r. 1418-1450) ordered a survey of all goods, including domestically produced herbal medicine, and levied taxes on them. For this purpose, he asked scholars to write geography books in order to make a list of these plants based on previous works of Hyangyak medicine. He also endeavoured through various means to build a national medical system, for example by assigning doctors to underserved regions and encouraging medical education. The objective of Hyangyak medicine in this period was nation-building and the establishment of a corresponding nationwide medical system.

Compendium of Prescriptions from the Countryside, a massive set of 85 books written in rapid succession and published in 1433, included 959 symptoms, 10,706 prescriptions, 1,476 acupuncture treatments and moxibustion methods, the materia medica of Hyangyak, and processing methods for herbs. It represented a dramatic increase in length compared with Compendium of Prescriptions from the Countryside for Universal Relief (1399), composed of 30 volumes, and the three-volume Emergency Prescriptions from the Countryside (mid-thirteenth century). This was the result of actively adopting vast numbers of prescriptions from China into Hyangyak medicine. When selecting a prescription, the most important criterion was whether the prescription could be prepared from only the 703 herbs native to Chosun. ${ }^{(21)}$

Compendium of Prescriptions from the Countryside was not used much after the sixteenth century. However, it was reprinted in 1633, three years prior to the war with the Qing, and in 1941, during World War II. Just as Hyangyak Medicine was emphasised during the thirteenth-century war with Yuan, it was republished in preparation for these subsequent wars. The 1940 s in particular were a time when goods were so strictly regulated that medicinal herbs were distributed by the government.

Ultimately, Compendium of Prescriptions from the Countryside is not a compilation of a uniquely Korean medicine (22) or a book that brought about independence in medicinal herbs, (23) but rather should be regarded as a book in which Chinese medicine was actively adopted from a local Korean medical viewpoint, a compilation of East Asian prescriptions composed from a Hyangyak perspective, with the objective of alleviating national finances in time of war and contributing to the building of a national medical system.

Since the sixteenth century, no medical text focusing on Hyangyak or with the word "Hyangyak" in its title has been published. However, the Synopsis of the Medical World (醫林撮要), published in the sixteenth century, includes many more Hyangyak prescriptions than later works. ${ }^{24)}$ Also, in Donguibogam (東醫寶鑑), published in 1613, Hyangyak prescriptions appear at the back of each chapter under the category of "Simple Prescriptions." In the Herbal Medication volume of Donguibogam, all Materia Medica are classified into "Hyangyak" and "Dangyak" (i.e., herbal medicine from China and other countries, as opposed to Hyangyak), and many later Korean medical texts follow this classification. Due to a lack of understanding, Kim suggested that Hyangyak medicine went into decline after the sixteenth century. Rather, there was no social need for preparing prescriptions only with Hyangyak after the sixteenth century, and Hyangyak therefore received less emphasis.
The medical tradition of emphasising Korean herbal medicines and using Korean herbs as much as possible was considered important for many different reasons, depending on the period. Hyangyak was the result of the Korean people's endeavour to protect and conserve Korean herbal medicines at a time when various medicinal herbs were being imported.

\section{Period of compilation of East Asian medicine (fifteenth to early seventeenth century)}

This third period was a time of compiling various treatment methods according to symptoms. At the begin of the period, from the fifteenth to the sixteenth centuries, Chosun was a well-developed and stable country where society, economy, culture, and technology were highly developed by the Neo-Confucians who founded it, but war with Japan (1592-1598) brought many changes.

Compendium of Prescriptions from the Countryside (1433) was published in accordance with their thinking. The compilation of Classified Assemblage of Medical Prescriptions (醫方類聚), begun in 1443, was completed in 1445 with 365 volumes. Nevertheless, it was not published right away. Rather, it underwent a long period of proofreading, and was not actually completed until 1477. During this proofreading period, about 70 officials who did not provide satisfactory results were punished, while those who finished their work well were rewarded, an indication that this was one of the most important projects carried out by the early Chosun dynasty. This book is considered one of the medical texts with the greatest quantity of information in the East Asian region, with about 260 volumes and 87 chapters extant.

Each of the 87 chapters is composed of Theories (理論), Prescription Methods (方藥), Food Therapy (食治), Taboos (禁忌), Conduction Exercise (導引), and Acupuncture and Moxibustion (鍼炎). Compared with most other medical texts, which are composed of theories and prescriptions, this work attempts to include various treatment methods in combination. Acupuncture and moxibustion methods are also written at the end of each chapter of Compendium of Prescriptions from the Countryside, which was published earlier, and in Donguibogam, which was published later. Moreover, food therapy is the key to Hyangyak medicine, which includes it in every chapter in the form of "Simple Prescriptions" (單方). Many accounts of healing the body through the consumption of clear tea are also mentioned in The Daily Records of Royal Secretariat of Chosun Dynasty (承政 院日記), which contains detailed records on the royal family of Chosun. (25) Likewise, in this book, Theories (理論), Diagnosis (診脈), Food Therapy (食 治), Taboos (禁忌) and Conduction Exercise (導引) are provided to cover all possible treatments for each disease.

Each of the subdivisions under the 87 chapters also includes excerpts categorised by important medical texts of the day. Since the excerpts are arranged by the date of publication and names of the source books, it

20. Kang Yeonseok, Ahn Sangwoo et al., Series of Biographies of Medical Figures. 4, Bang Saryang, Korean Institut of Oriental Medicine, 2010, pp. 87-123.

21. Kang YeonSeok, "The Writing of 'HyangYakJipSungBang (鄉藥集成方)' and Medical Exchanges between Korea and China during the 15th Century," op. cit., pp. 213-217.

22. Miki Sakae, op. cit., pp. 125-132.

23. Kim Doojong, op. cit., pp. 206-219.

24. Kim HongGyun, "The Influence of HyangYaklipSungBang (鄉藥集成方) on Later Cenerations," Establishing Database for HyangYakJipSungBang, Korea Institute of Oriental Medicine, 2001, pp. 105-186.

25. Kim Jongoh, A Study of the Medicinal Tea of Joseon, Kyunghee University, PhD dissertation, 2010, pp. 11-13. 
serves as a virtual history of East Asian medicine in itself. It is worth mentioning here that this practice was contrary to that of many prescription books published in China, which were written without citing other works. Many lost medical texts are being restored through reference to this Korean book, and similar content or reference notes can be made into annotations. ${ }^{(26)}$ Because it is classified by subject and cites all sources, and because the citations are also arranged chronologically, this work helps clarify the publication dates of old medical texts. A medical text called $A$ Hundred Essential Prescriptions for Prevention (備預百要方), ascertained to have been written in early thirteenth-century Goryeo, was restored in this way, (27) as was Prescriptions for Mending Injuries Handed Down from a Hermit (仙授理傷續斷方), which had previously been considered a medical text from Tang, but proved to be a book written in the late Yuan dynasty. (28) Compendium of Prescriptions from the Countryside and Classified Assemblage of Medical Prescriptions also include reference notes for every sentence, a punctiliousness that has become another tradition of KM.

Unfortunately, this book involved a huge amount of work, and only 30 sets were created, most of which have been lost; only one full set remains in the Japanese Library of the Imperial Household Agency, the result of plundering by Japanese soldiers during the Japanese Invasion of Korea in 1592-1598. Currently 252 volumes, about 9.5 million characters, and about 50 thousand prescriptions remain extant. Since it is said that all prescriptions are classified into 120,000 types in China, it would be no exaggeration to say that all prescriptions in the East Asian region before the early fifteenth century are compiled in this book. ${ }^{(29)}$ The reason that there was a sudden increase in the number included in the aforementioned Compendium of Prescriptions from the Countryside in the fifteenth century is because it followed this writing method.

The scientific attitude and interest of Neo-Confucians played a leadership role in Chosun society at that time. In early fifteenth-century Chosun, young Neo-Confucian officials were assigned to the Hall of Worthies, which was founded under the direct order of the king, and were not only associated with works regarding the training of the younger generation, researching, writing official documents, preparing examination for recruiting officials, and managing royal records, but were also involved in compilation projects covering all fields of study. A record from the year 1466 in The Annals of the Chosun Dynasty (朝鮮王朝實錄) refers to "categorically compiling" (類聚) all books on each topic, namely Book of Change (易), Astronomy ( 天文), Geography (地理), Medicine (醫), Divination ( 卜筮), Poem Writing (詩文), Calligraphy (書法), Musicology (律呂), Agriculture (農桑), Stock Raising (畜牧), Translation (譯語), and Calculation Methods (算法). Most of these texts were written in the itemised format adopted by NeoConfucian scholars. Most important medical texts of Chosun, such as Compendium of Prescriptions from the Countryside, Classified Assemblage of Medical Prescriptions, and Donguibogam were also written in an itemised format. ${ }^{(30)}$

A record states that a book called Essentials of Medicine (醫門精要), an abridged version of the Classified Assemblage of Medical Prescriptions (around one fifth of the original), was compiled from 1493 onward, and that 50 volumes were published in 1504 . However, the book has not been handed down. A Collection of Sores and Rashes (瘡疹集) and Emergency Prescriptions (救急方) were written during the reign of King Sejo (r. 14551468), and Emergency Simple Prescriptions (救急簡易方 ), Emergency Prescriptions Easy to Treat (救急易解方), and Prescriptions for Dispelling Pestilence (續辟盒方) were written during the reign of King Seongjong (r. 1469-
1494). All these medical texts covered a limited number of diseases in the specialised fields of communicable diseases or emergency diseases. (31) These were related to the development of a system for handling epidemics in Chosun.

A record in The Annals of the Chosun Dynasty refers to a severe epidemic that arose in the spring of 1451 and died down in the fall of 1452 . When the epidemic that started in the northwestern region of Seoul spread as far as near the boundaries of Seoul, the king even considered moving the capital elsewhere. A local official was initially in charge of managing this situation, but a minister of the central government was put in charge in April 1451. In July, when the situation deteriorated to a state of national crisis, the Office of the Premier was put in charge. Only doctors from the central government were dispatched at first, but after the epidemic spread, the following measures were taken: 1) The Office for Saving People (活民院) was refurbished for isolating patients; 2) bath and fomentation facilities were provided; 3) heating materials, food, and medication were given to patients; 4) local officials referred patients to the Office for Saving People; 5) when people were found to be unaware of the aforementioned measures, the official in charge would be punished. (32)

Doctors were dispatched by the central government to observe the epidemic, return, and report the symptoms. The central government's Royal Clinic then published a customised medical text for the epidemic and distributed it to local districts. Since these texts had to be published as soon as possible in order to treat specific diseases, the print run was inevitably very limited. It is thought that in this type of system, the aforementioned books on epidemics published and used specifically for the treatment and management of epidemics may have been a cause of the lesser popularity of warm disease studies (溫病 - wen bing), which developed during between the seventeenth and nineteenth centuries in China.

The late sixteenth century saw publication of Synopsis of the Medical World by Yesu Yang. Compendium of Prescriptions from the Countryside and Classified Assemblage of Medical Prescriptions were more related to the medical ideology of the Song and Jin, while Synopsis of the Medical World and Donguibogam were more closely associated with the medical ideology of the Yuan and Ming. The Synopsis of the Medical World combined the contents of Korea's Compendium of Prescriptions from the Countryside and China's Orthodox Transmission of Medicine (醫學正傳 Yixue zhengchuan), Introduction to Medicine (醫學入門 - Yixue rumen), and Recovery from All Ailments (萬病回春 - Wanbing huichun).

The medicine of this period can be summarised in the following aspects: 1) medicine became an important part of national policy; 2) Neo-Confucians led the national medical system and compilation of medical texts; 3 ) an itemised description style was applied to medical texts; 4) citation

26. Ahn SangWoo, A Bibliographical Researches on EuiBang-YooChui (醫方類聚), Kyunghee University, PhD dissertation, 2000, pp. 36-40.

27. Ahn SangWoo, "Historical research on Korean medical book BiYeBaekYoBang," Journal of Korean Society of Medical History, vol. 13, no. 2, 2000, pp. 3-21.

28. Kim YoungGon, "Study of Ancient traditional medical text Lisangsokdanbang (理傷續斷方) through the Uibangyuchwi," Journal of Korean Society of Medical History, vol. 20, no. 1, 2007, pp. $22-29$.

29. Ahn SangWoo, op. cit., pp. 1-4.

30. Kang YeonSeok, Ahn SangWoo et al., Series of Biographies of Medical Figures 2, Korea Institute of Oriental Medicine, 2008, pp. 11-18, 93-103, 145-151, 173-177; Kang Yeonseok, Ahn Sangwooet al., Series of Biographies of Medical Figures 3, Korea Institute of Oriental Medicine, 2009, pp. 11-34, 89-97, 163182.

31. Ahn SangWoo, op. cit., pp. 20-31.

32. Kang Yeonseok, Rewriting the History of Korean Medicine: Endeavours of Korean Medicine to Fight Epidemics, Ohmynews.com, November 4th, 2009. 
sources were clarified; 5) medical texts were arranged according to the classification of symptoms; 6) various treatment methods were compiled under symptoms; 7) medical texts of this period covered not only Korean medicine but also medical texts published in China; 8) medicine of this period included all medical knowledge up to the sixteenth century; 9) the government handled epidemics in a systematic fashion.

\section{Independent development of Korean Medicine (seventeenth to nineteenth century)}

This fourth period of the history of KM was a time of publication and rearrangement of Donguibogam as well as exploration of new medicine. While at war with Japan (1592-1598) and with the Qing regime (1627, 1636-37), Chosun was cut off from the rest of the world and formed its own unique culture in the eighteenth century. The nineteenth century was when direct exchanges with the West began.

In the early seventeenth century, Heo Jun (許浚 1539-1615), who became a doctor at the court of Chosun at the age of 29 , made history in 1613 with the publication of a book that was to have a major influence on the evolution of KM right up to the present day: Donguibogam.

In his "Note to Readers," Heo explains the reason for the name of the book. Heo classified Chinese medicine into two groups: Northern Medicine (北醫) of the Dong Yuan sect (東垣學派) ${ }^{(33)}$, and Southern Medicine (南 醫) of the Danxi sect (丹溪學派). ${ }^{(34)}$ After these two sects appeared in the thirteenth to fourteenth centuries, East Asian medicine developed into a completely different medicine from what it used to be, under the influence of Neo-Confucianism rather than of Buddhism. At the same time, Heo named the medicine of Chosun "Dongui" ( kor. trans. of 東醫 - Eastern Medicine) because he thought it had constructed a distinctive domain of medicine after being handed down over an extended period. Also, since this book was eligible to become a standard medical text, he gave it the name "Bogam" (kor. trans. of 寶鑑 - Treasured Mirror). From this time on, KM became known as "Dongui", and even now in North Korea, traditional medicine is referred to as "Dongui" or "Goryeo Medicine." The preface to a copy republished in China in 1766 says, "A treasure of the world can now be shared with the world." The book's reputation can be assessed by the fact that it was published more than 30 times overseas.

Donguibogam is composed of five sections in 25 volumes: four volumes for the "Internal Bodily Elements" section (內景篇), four volumes for the "External Bodily Elements" section (外形篇), 11 volumes for the "Miscellaneous Disorders" section (雜病篇), three volumes for the "Herbal Medication" section (湯液篇), one volume for the "Acupuncture and Moxibustion" section (鍼炎篇), and two volumes for the "Table of Contents" (目錄).

The first three sections include 1,136 disorders, 4,497 multiple prescriptions (復方), and 1,996 simple prescriptions (單方). Both the "Internal" and "External Bodily Elements" sections classify diseases according to whether they occur inside or outside the body. The "Miscellaneous Disorders" section describes various diseases that cannot be explained using bodily elements. These standards of disease classification were first attempted by Heo, who directed the publication of this book. Many subsequent Korean medical texts followed this format. Under each disease that is classified in a more defined way are inquiries into existing theories, names, and disputes, pulsation methods, treatment methods, prescriptions, life preservation methods, acupuncture and moxibustion, and simple prescriptions. The detailed classification of divisions ( 綱) and subdivisions (目) suggests that Donguibogam was written more systemically than the earlier Compendium of Prescriptions from the Countryside or Classified Assemblage of Medical Prescriptions. This kind of systemic classification can be said to have reached the most detailed level in East Asian medicine. It is reflected in the fact that two volumes were allocated to the Table of Contents, comprising a large proportion of the total 25 volumes. ${ }^{(35)}$

Especially in the introduction of the "Miscellaneous Disorders" section, general remarks are first given on the order of diagnosis of diseases and treatments such as Laws of the Universe (天地運氣), Detection (審病), Differentiation (辨證), Pulse Diagnosis (診脈), Prescription and Administration (用藥), Emesis (吐), Perspiration (汗), and Laxation (下). An important characteristic is that diseases and patterns of diseases are considered at the same time, with directions that during diagnosis, "detecting diseases" should precede "differentiating patterns."

In the "Herbal Medication" section, introduction to Herbology was first written in the Methods of Decoction (湯液序例), followed by the particularities on 1,212 types of materia medica described in 15 sections. Imported medicinal herbs were designated with the term "Dang" (唐). There were no specific indications for "Hyangyak," but Korean names for 637 kinds of materia medica were noted. (36)

Donguibogam has the following characteristics: 1) it rearranged East Asian medicine through a detailed table of contents; 2) the life-nurturing ideology of Taoism was set forth from the perspective of Neo-Confucianism; 3) diseases were classified according to body parts; (37)4) it showed highly developed perception regarding several diseases; (38) 5) it reflected various theories equally, with a slightly greater emphasis on the Theory of Yin Nourishment (滋陰); (39) 6) it resettled various different opinions by presenting suitable theories depending on the kinds of diseases.

New Edition of Universal Relief (濟衆新編 1799) and Compilation of Formulas and Medicinals (方藥合編 1884 ) both classify diseases the way Donguibogam did. The former in particular was a summary of essential information from the immense Donguibogam. In both books, the vast amount of information in the "Herbal Medication" section (湯液編) was replaced with "The Song of Medical Properties" (藥性歌), which is comprised of heptametrics poems ${ }^{(40)}$. But a distinction was drawn between Hyangyak and Dangyak as in Donguibogam.

While Donguibogam was being reconstructed, an attempt to create new medicine exceeding its achievements was being made. Gyujun Lee (1855-

33. Editor's note: Li Dongyuan (1180-1252) focuses his approach to pathology on the internal origins of disease, particularly on the weakening of the spleen and stomach, which he considered the root cause of many diseases, including manifestations of heat due to a deficiency of qi. His school mainly prescribes the use of sweet and warm ingredients in order invigorate the qi of the spleen (cf. Éric Marié, Précis de médecine chinoise, Escalquens, Dangles, 2008, p. 56).

34. Editor's note: Zhu Danxi (1281-1358) believed that there was often an excess of yang and a deficiency of yin. The guiding principle of his therapeutic system was therefor to enrich the yin and control Fire, especially the xianghuo (相火 - Fire Minister) related to the functional activity of the liver and kidney (ibid.).

35. Kim Namll, aforementioned website.

36. Ibid.

37. Kim Namll, aformentioned website.

38. Cho SunYoung, The Medical History of SoGal (消渴 ), Kyunghee University, PhD dissertation, 2009, pp. 153-156.

39. Cha WungSeok, "Comparative studies on EuiHaklpMun and DongEuiBoGam," Journal of Korean Medical History, vol. 13, no. 1, 2000, pp. 111-128.

40. Editor's Note: Given the large amount of information that has to be memorised in order to practice Chinese medicine, students and disciples, masters and teachers have often used poems as mnemonic devices. This kind of poetry continues to be passed down today. 
1923), a Neo-Confucian scholar in nineteenth-century Gyeongsang Province, wrote Reconstructing Donguibogam (醫鑑重磨) and Essentials of Plain Questions (素問大要). The former conveys the meaning of "reanalysing Donguibogam." In this book, Lee strongly criticises the part of Donguibogam that emphasises the Theory of Yin Nourishment over other theories. Also, in Essentials of Plain Questions, he suggests "Yang Support Theory" (扶陽論), which focuses on the fire and mind of "the heart" (心). ${ }^{(41)}$ It is a reinterpretation of the Internal Classic (內經) from a Korean perspective. ${ }^{(42)}$ Pupils of Lee still utilise unique pulse-taking methods and prescriptions, and have formed a modern academic society of practitioners from all over the country, centred on those from Gyeongsang Province. ${ }^{(43)}$ It may be worthwhile to carry out a comparative study of this society and a local medical system in China during the Ming and Qing dynasties called Xin'an Medicine, because the two have many things in common. ${ }^{(44)}$

Jema Lee (1838 1900) founded a "Constitutional Medicine" based on Mind-Nature (心性) by writing Longevity and Life Preservation in Eastern Medicine (東醫壽世保元) ${ }^{(45)}$. Like Gyujun Lee, Jema Lee emphasised the mind of "the heart," and he categorised constitutions according to the sizes of the lungs, spleen, liver, and kidneys. Lee regarded Jun Heo as one of the most important medical figures, along with Zhongjing Zhang (張仲 景 ). As many prescriptions of Shanghanlun are used, this can be said to be a reanalysis of cold damage from a Korean perspective. This is called "Four Constitutional Medicine" (四像醫學) or "Sasang Constitutional Medicine" (四像體質醫學), and many related academic societies and books currently exist. ${ }^{(46)}$ In the Yanbian Korean Autonomous Prefecture (延邊朝鮮族自治州) in China's jilin Province (吉林省), it is called "Chosun Medicine" (朝醫 "Joeui" for kor. trans.).

The period of Hyangyak Medicine (thirteenth -fifteenth centuries) and the period of compilation of medicine (fifteenth-sixteenth centuries) both had close medical exchanges with China. While continuing medical exchanges with neighbouring countries, KM began to develop in a much different direction from TCM after the publication of Donguibogam (seventeenth century). While the tendency to reject Qing culture after the defeat in the Manchu War (1636) can be considered an external factor, internal factors included the self-confidence Chosun had gained from Donguibogam, and the belief that enough could be achieved without Qing medicine.

KM subsequently gained the following characteristics:

First, Donguibogam replaced Chinese classics of TCM such as the Internal Classic, Shanghanlun, Synopsis of Prescriptions of the Golden Chamber (金 匱要略), Classic of Difficult Issues (難經), and Shennong's Classic of Materia Medica (神農本草經), and assumed their status in the medical canon. This was also the tradition handed down from Compendium of Prescriptions from the Countryside or Classified Assemblage of Medical Prescriptions. Neither of them regarded the aforementioned books of the medical canon as important references, but many Tang and Song works such as Treatise on the Pathogenesis and Manifestations of All Diseases (諸病源候 論 ), Medical Secrets of an Official, Essential Prescriptions Worth a Thousand Pieces of Gold, Three Causes of Diseases (三因方), Peaceful Holy Benevolent Prescriptions (太平聖惠方), and Re-edited Classified Materia Medica were regarded as important. It was only in the fifteenth to seventeenth centuries that some medical texts became part of the medical canon in China. It seems that around the same time in Korea, Donguibogam took over this status, following the tradition of the previous two Korean books.
Second, standardisation of KM has taken place over the last 400 years in accordance with Donguibogam, which provided standards not only for disease classification, but also for the composition and quantity of prescriptions. Thus, even prescriptions with the same name, composition, quantity, or processing methods came to differ in Korea and China in many cases. Though such medical classics were already introduced to Korea a thousand years earlier, and had been used in state examinations for medical officers since the Goryeo dynasty, they did not have absolute authority in Korea as they did in China.

Third, practical measures were taken when writing medical texts or studying medicine. Those who emphasised medical classics were NeoConfucian scholars. They were trained to explain the nature of the world, and thus they described various theoretical systems and had disputes with one another. Their way of studying medicine was to "first review the Confucian classics." However, the medical texts of Chosun stressed describing diseases over talking theory; The Annals of the Chosun Dynasty and the "Note to Readers" in Donguibogam say that when studying medicine, one should "first study materia medica."

Fourth, the perspective on disease emphasises mind and body over external factors. Traditionally in East Asian medicine, problems regarding external pathogenic qi and internal healthy qi were considered the causes of diseases. Donguibogam classified diseases according to body parts and emphasised life-nurturing in accordance with Neo-Confucian tradition. In the "Miscellaneous Disorders" section, diseases related to the wind pathogen, cold pathogen, summer heat pathogen, dampness pathogen, dry pathogen, and fire pathogen are not separately classified as externally contracted but rather are included in the category of internal damage. This trend became more dominant in the nineteenth century and led to the publication of Reconstructing Donguibogam, which emphasises yang qi in the body, and Longevity and Life Preservation in Eastern Medicine, which talks about constitutions. ${ }^{(47)}$

Fifth, different measures were taken for different kinds of epidemics. Around the same time, the study of warm disease was very popular in China, and research on the Chinese classic of the Shanghanlun made great progresses in Japan. Applying measures based on cold damage and warm disease means using standardised pattern differentiation and prescriptions

41. Editor's note: There are five organs in Chinese medicine: the heart and lungs are yang, while the spleen, liver, and kidneys are yin. But among "yang" organs, the heart is yang and the lungs are yin, and among "yin" organs, the liver is yang, while the spleen and kidneys are yin. In this classification, the heart is the yang of yang. Therefore, yang support is inseparable from therapeutic strategy focusing on the heart. (Éric Marié, Précis de médecine chinoise, op. cit., 2009, p. 98).

42. Kwon OhMin, A Study on Shukgok, Lee Gyu-Jun's Medical Ideas, Kyunghee University, PhD dissertation, 2010, pp. 35-41.

43. Kim Taewoo, Medicine without the Medical Gaze: Theory, Practice and Phenomenology in Korean Medicine, State University of New York - Buffalo, PhD dissertation, 2010.

44. Kwon OhMin, op. cit.

45. Editor's footnote: "Korean Constitutional Medicine, while little understood in the U.S., is well known for its effectiveness in both Asia and Europe. It already classifies humans into four genetic types, termed 'constitutions', then further into subdivisions. As a result, both the treatments and herbal medicines are prescribed according to a patient's particular genetic type. In general, most doctors decide medical treatment or examination based on the disease of the patient. However, Korean Constitutional Medicine uses different prescriptions and treatments according to the state of the patient's mind - in other words his heart. "Treatment that works for one patient may be ineffective or harmful to another simply because of their hereditary differences. The ability to individualize the diagnosis is the key to successful treatment", says Dr. Puramo Chong, who is renown as one of the world's foremost practitioners of KCM" (www.puramo.com/new/html/medicine.htm).

46. Kim Taewoo, Medicine without the Medical Gaze: Theory, Practice and Phenomenology in Korean Medicine, State University of New York - Buffalo, PhD dissertation, 2010, pp. 14-26.

47. Kim Namll, aforementioned website. 
on epidemics. However, Korea held fast to the national system of controlling epidemics that had been settled since early Chosun, as well as to the tradition of applying different treatment measures to different epidemics. Research on cold damage or warm diseases was not popular. Additional research would be helpful, especially given that Europeans landed in Korea later than they landed in China and Japan, and epidemics in Korea are therefore likely to have been quite different from those in China or Japan. The tradition of looking for the cause of disease inside the body rather than outside could be another reason.

\section{Exchanges between Asian traditional and Western medicine (twentieth to twenty- first centuries)}

We are now in the fifth period of the history of $\mathrm{KM}$. This period has been a time of struggle for KM to gain official acceptance by obtaining status in the legal system, and also to adapt itself to the field of modernised research. After 1905, Japan gained sovereignty over Chosun, and from 1910 to 1945 Chosun was ruled by Japan. True modernisation began after World War II, and Korea has made startling economic progress over the past 30 years.

In 1900, before Japan took over the country, the "Doctor's Rules" (醫士規 則 ) regarded all those who learned KM or Western medicine as "medical doctors." However, once Japan took over Chosun, doctors schooled in KM were no longer allowed to work in national hospitals, starting from 1907. This was because Japanese Parliament had already decided in 1895 to eradicate traditional medicine from the national medical system. But it became difficult for Japan to produce Western medical doctors in colonised Chosun due to the high cost; this led to the promulgation of the Medical Practitioner's Rules (醫生規則) in 1913. However, Western medical doctors were referred to as "Euisa" (kor. trans. of 醫師 - doctors), while Korean medical doctors were referred to as "Euisaeng" ( kor. trans. of 醫生 - medical students). ${ }^{(48)}$ The colonisation of Chosun widened the social gap between the two, leading to the mutual hostility that exists between them in Korea. The biased policy toward KM was reflected in education as well, and KM was not included in university education until independence in 1945. ${ }^{(49)}$

Fortunately, the Korean National Assembly reintegrated KM into the national medical system on 25 September 1951, and 1952 saw the founding of an institution specialising in education in KM. At present, colleges of Oriental medicine exist in 11 private universities and one national university, and Oriental pharmaceutical departments exist in three private universities. There are currently more than 20,000 Korean medical doctors, around 1,000 Korean medical pharmacists, some 600 professional researchers, about 12,500 Korean medical clinics, and around 200 Korean medical hospitals. Approximately 800 Korean medical doctors and 120 Korean medical pharmacists are produced each year.

In the 1980s, as medical insurance policies were being formulated, demands from young Korean medical doctors led to the inclusion of acupuncture, moxibustion, and some types of traditional drugs in medical insurance coverage in 1987. For a number of reasons, TM treatments continue to make up around 4-5 percent of total medical insurance coverage, in spite of steady demand.

The unequal status of KM and Western medicine did not improve until the 1990s. In the 1980s, as more and more students with high grades began applying to Korean medical colleges, young students and practition-

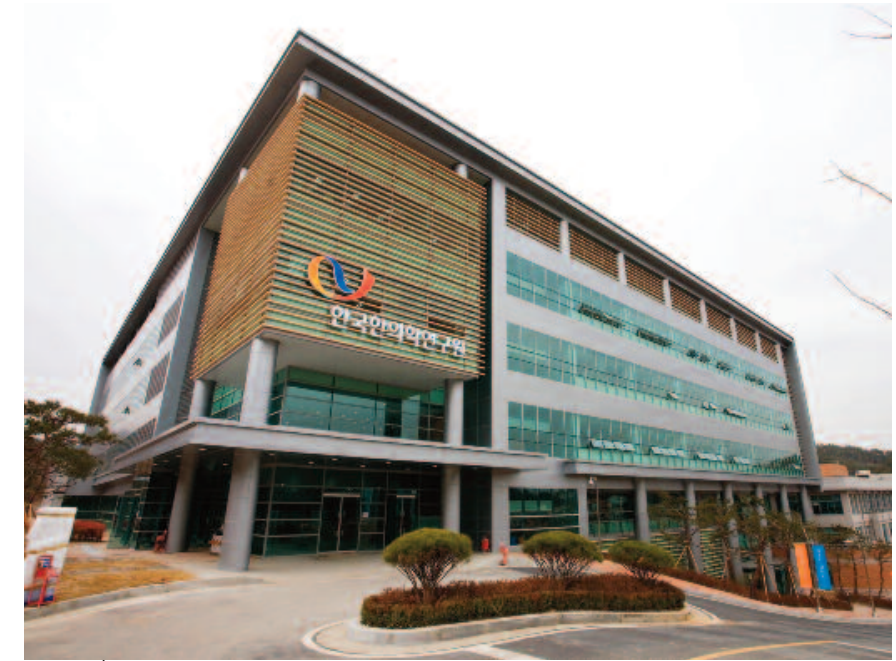

The central building of the Korean Institute of Oriental Medicine (KIOM), founded in 1994. (c) KIOM

ers increasingly criticised government policies. The period from March 1993 to March 1997 saw numerous campaigns targeting the government, such as long-term boycotts of lectures, and street assemblies led by students and practitioners.

The government subsequently clarified its intention to raise the status of KM and enforced various policies. The Korean Institute of Oriental Medicine, the only government-funded research institute of Oriental medicine, was founded in 1994, and the central government also established a department assigned exclusively to dealing with policies related to KM. Universities began establishing departments of Korean medical pharmaceutics in 1995. Starting in 1998, Korean medical public health doctors began to be assigned to community health centres nationwide. The "Bill for Fostering Korean Medicine" was passed in 2003, and Roh Moo-Hyun, a Korean medical physician, became President of Korea. In 2007, a School of Oriental Medicine was founded in a national university.

With active support from the government, students ranking in the first percentile selected officially by the State examination system in colleges of Oriental medicine, providing KM with the best pool of talent among all countries that practice traditional medicine. ${ }^{(50)}$ Nevertheless, it is also true that nearly half of KM's 20,000 doctors are in their 20 s or 30 s. The sudden increase in the number of doctors in the 2000s has given rise to generational conflicts resulting from problems such as underemployment. Many local self-governing bodies are currently investing in the promotion of the Korean medical industry, and an EXPO on World Traditional Medicine is scheduled to be held in 2013 in Sancheong, Gyeongsang Province, in commemoration of the $400^{\text {th }}$ anniversary of the publication of Donguibogam. Experts of traditional medicine from more than 30 countries are expected to participate in this event.

With the arrival of the twentieth century, the influence of Japanese medicine on KM was paradoxically stronger than that of Chinese medicine until

48. Translator's note: In Chinese, yishi (literally "medicine professor") and yisheng (literally "medicine student") can both be translated as "doctor," but the former often has an honorary connotation.

49. Maeng Woongjae et al., op. cit., pp. 471-516.

50. Kim Taewoo, op. cit., pp. 40-44. 
the 1970s. In the early twentieth century, official names such as "Hanbang" (kor. trans. of 漢方- Kampo in Japanese), "Hanuihak" (kor. trans. of 漢醫學 - "Korean medicine"), and "Dongyanguihak" ( kor. trans. of 東洋醫 學 - "Oriental medicine") were commonly used due to Japanese influence. Japanese research on Shanghanlun was also introduced to Korea, and many translated texts appeared. Although "Hanuihak" has been the official name in Korean since 1981, the English version is still "Oriental Medicine," which is a translation for "Dongyanguihak," and there have been calls for a revision.

After the 1980s, the texts and education system of modern TCM were introduced to Korea. In addition, basic subjects relating to medicine (biology, organic chemistry, biochemistry, anatomy, physiology, pathology, pharmacology, preventive medicine, medical statistics, etc.) and clinical medicine (diagnostics, clinical pathology, diagnostic radiology, emergency medicine, internal medicine, rehabilitation medicine, otolaryngology, dermatology, ophthalmology, psychiatry, neuroscience, etc.) are now included in the sixyear curriculums of Oriental medical colleges, taking up more than half of the allotted class time. The status of Donguibogam, the standard of KM for the last 400 years, is therefore at stake.
Since the 1990s, various debates and disputes have been carried out within and outside of KM circles on the topics of modernisation (standardisation, scientific experimentation, industrialisation) and globalisation of KM. The details are as follows: First, dispute rather than collaboration is increasing between representative associations for Korean medical doctors, medical doctors, and pharmacists, because of limited resources. Second, there is a major argument ongoing between practitioners in primary medical practices and specialists who work in Korean medical hospitals, as well as between the younger and older generations, on how research and education should be oriented in this time of co-existence between traditional medicine and modern medicine and science. Third, competition exists between TCM and KM over who speaks for East Asian medicine in various international meetings. Fourth, even within the realm of traditional medicine, disputes exist between the methodologies of Donguibogam, the Four Constitutional Medicine, and various assertions made by TCM or Japanese medicine. If conflicts between professions and generations are ultimately reasonably resolved, the various debates ongoing in Korean medical circles could form the foundation for the birth of a new medicine. 